ESTUDOS RBE?

\title{
Gestão da educação escolar indígena diferenciada: contradições, limites e possibilidades
}

Lúcia Bruno

\section{Resumo}

Aborda o processo de implementação das políticas de educação indígena no Brasil nas últimas décadas e discute as contradições que emergem do encontro de duas lógicas sociais antagônicas: a que afirma a organização social das comunidades indígenas alicerçada sobre os princípios da reciprocidade e da solidariedade e a lógica burocrática que orienta as ações do Ministério da Educação (MEC) e das secretarias de Educação nos âmbitos estadual e municipal. Essas contradições colocam novos desafios para as comunidades indígenas em vários níveis e dimensões. Sendo pesquisa em andamento, limita-se a problematizar aspectos centrais a partir da literatura sobre a temática e de observações de pesquisa de campo realizada na aldeia Krucutu, em Parelheiros-SP, no primeiro semestre de 2009.

Palavras-chave: educação escolar indígena; gestão; conhecimento; aprendizagem. 


\section{Abstract \\ Indigenous education management: contradictions, limits and possibilities}

The present study focused on the indigenous education policies implementation during the last decades in Brazil and it discusses the emerging contradictions from the meeting of two antagonistic social logics: the first presents the indigenous communities social organization based on the principles of solidarity and reciprocity; the second the bureaucratic logic that guides the actions of the Ministry of Education and the Education Secretaries in state and municipal levels. These contradictions imply some new challenges to the indigenous communities in several levels and dimensions. As it is an unfinished research, the article just presents central aspects according to the literature and some field observations in the Krucutu village in Parelheiros-SP during the first semester of 2009.

Keywords: indigenous education; management; knowledge; learning.

\section{Educação escolar indígena diferenciada: breve histórico}

Nas últimas décadas do século 20, as lutas e as reivindicações de diversas etnias indígenas pelo reconhecimento de seus territórios e outros direitos resultaram na inclusão de artigos na Constituição Federal de 1988, que busca contemplá-los. Neste sentido, vale ressaltar os artigos 231 e 232, que lhes asseguram o reconhecimento dos direitos sobre os territórios que ocupam, sua organização social, costumes, línguas, crenças e tradições. Esse reconhecimento foi acompanhado de uma série de mudanças relativas à gestão e à condução das políticas voltadas para essas populações. O governo Collor (1990-1992), logo no início, por meio de decretos assinados em 4 de fevereiro de 1991, atribuiu a diferentes ministérios e órgãos federais responsabilidades antes concentradas na Fundação Nacional do Índio (Funai). São eles: o Decreto $n^{0} 23$, que colocou a assistência à saúde das populações indígenas sob a responsabilidade da Fundação Nacional de Saúde (Funasa); o Decreto no 24, que estabeleceu que as ações de proteção ao meio ambiente em terras indígenas seriam coordenadas pela Secretaria do Meio Ambiente (SMA) e executadas pelo Instituto Brasileiro do Meio Ambiente (Ibama); o Decreto no 25, que subordinou os programas e projetos para a autossustenção das comunidades indígenas ao Ministério da Agricultura e da Reforma Agrária (Mara); e, finalmente, o Decreto $n^{\circ}$ 26, que definiu o MEC como instância 
coordenadora das ações referentes à educação escolar indígena no País em todos os níveis e modalidades de ensino.

O MEC, por sua vez, delegou às Secretarias Estaduais e Municipais de Educação a responsabilidade de desenvolverem as ações neste campo. Dois meses depois, os ministros da Educação, Carlos Chiarelli, e da Justiça, Jarbas Passarinho, editaram a Portaria n 559, que garante às populações indígenas: "uma educação escolar básica de qualidade, laica e diferenciada, que respeite e fortaleça seus costumes, tradições, língua, processos próprios de aprendizagem e reconheça suas organizações sociais"; "o acesso ao conhecimento e o domínio dos códigos da sociedade nacional, [tendo em vista] a participação plena na vida nacional em igualdade de condições, enquanto etnias culturalmente diferenciadas"; e, ainda, "o ensino bilíngue nas línguas maternas e oficial do país, atendidos os interesses de cada grupo indígena em particular". Finalmente, define uma série de características específicas da educação indígena que deveriam ser observadas, como calendário, metodologias e conteúdos curriculares próprios, materiais didáticos bilíngues, etc. (Grupioni, 2008, p. 36).

Esta proposição de que os índios tinham direito a uma educação escolar diferenciada foi transformada em política estatal, assinalando uma importante mudança na concepção de educação indígena até então assumida pelo Estado: uma educação realizada em grande parte sob a orientação da evangelização missionária e do proselitismo religioso e voltada ao ensino monolíngue em português e à inculcação de valores, normas disciplinares e comportamentos considerados civilizados, visando, sobretudo, integrar as etnias e grupos indígenas na sociedade nacional.

A nova concepção de educação, em que se reconhece aos povos indígenas o direito de manter-se em sua própria cultura e organização social, resultou de ações articuladas de representantes de comunidades indígenas, de várias de suas associações, professores índios, antropólogos e linguistas vinculados ao meio acadêmico, indigenistas e associações científicas, tais como a Associação Brasileira de Antropologia e a Associação Brasileira de Linguística, e Organizações Não Governamentais que atuam neste campo.

Nos anos 90, vários documentos e ações surgiram para dar efetividade ao que a Constituição Federal estabelecia. Em 1993, o MEC criou o Comitê de Educação Escolar Indígena, e entregou a um colegiado, constituído por membros dos grupos acima referidos, a tarefa de elaborar uma política nacional de educação indígena, estabelecendo ações a serem implementadas e definindo programas a serem cumpridos. Esse Comitê elaborou as Diretrizes para a Política Nacional de Educação Escolar Indígena, que serviu de base para o MEC quanto à orientação dos sistemas estaduais de ensino no processo de adesão à nova proposta. Foram também elaborados o Referencial Curricular Nacional para as Escolas Indígenas (1998), os Referenciais para a Formação de Professores Indígenas, de 2002, e, no âmbito do Programa Parâmetros em Ação de Educação Escolar Indígena, documentos voltados à formação de professores indígenas, que integravam o conjunto de documentos dos Parâmetros Curriculares Nacionais em Ação implementado pelo MEC a partir de 1991. 
Esses documentos indutores de uma nova política escolar indígena estabeleciam que esta devesse se pautar pelos princípios e pela lógica social, política e cultural que estruturam as sociedades indígenas brasileiras, garantindo seus direitos culturais, tradições, memória histórica e línguas. De forma geral, toda a legislação produzida nesse período garante o uso das línguas maternas no processo escolar; o recurso a processos próprios de aprendizagem; educação intercultural, com acesso à língua nacional e a conhecimentos ditos universais; participação de grupos indígenas no planejamento e execução de programas; adoção de currículos próprios com o conteúdo cultural de cada grupo; materiais didáticos específicos e diferenciados; autonomia pedagógica e financeira das escolas; formação de professores indígenas e programas específicos para melhoria das condições de ensino; direito de criar suas próprias instituições de ensino; e criação de setores próprios para administrar a educação indígena, entre outros.

Em 2001, foi extinto o Comitê Nacional de Educação Escolar Indígena e, ao mesmo tempo, ampliada a participação dos técnicos dos sistemas de ensino das Secretarias Estaduais de Educação e dos professores indígenas, afastando, segundo Grupioni (2008, p. 57), associações indígenas, especialistas vinculados ao meio acadêmico, organizações não governamentais com longa tradição de atuação neste campo - todos os que tinham até então ocupado papel de destaque na formulação das políticas e na definição dos marcos conceituais do novo modelo de educação indígena. Esse modelo era constituído por princípios gerais de abrangência nacional, uma vez que deveriam se mostrar operativos em realidades culturais e etnográficas muito distintas entre si, organizando as relações entre as comunidades indígenas, a instituição escolar e o Estado.

Segundo Grupioni (2008, p. 56), a ideia era de que

\begin{abstract}
Entre a universalidade do que se propunha e a conjuntura particular de cada situação de interação de um grupo indígena com a escola, uma gama enorme de possibilidades se apresentava. Nos termos propostos nesses documentos, esse era o espaço a ser ocupado pelas comunidades indígenas, pelos pais dos alunos e por suas lideranças. Na prática, foi o espaço em que os técnicos dos sistemas de ensino passaram a atuar, disciplinando, legislando, restringindo.
\end{abstract}

Atualmente, os órgãos responsáveis pela educação escolar nas aldeias são o MEC, a Secretaria de Educação Continuada, Alfabetização e Diversidade (Secad/MEC) - que responde pelas políticas de formação de professores indígenas voltadas para a oferta das licenciaturas e do magistério intercultural e pela produção de materiais didáticos e paradidáticos específicos - e, finalmente, a Comissão Nacional de Educação Indígena (CNEI). Os recursos financeiros provêm do Fundo de Manutenção e Desenvolvimento da Educação Básica e de Valorização dos Profissionais da Educação (Fundeb), do Fundo Nacional de Desenvolvimento da Educação (FNDE), do Programa Dinheiro na Escola (PDE) e do Programa Nacional de Alimentação Escolar (Pnae). 
No Estado de São Paulo, a Secretaria de Educação, por meio da Resolução SE 147, de 29/12/, define os termos em que deverá se dar a organização e o funcionamento das escolas indígenas, estabelecendo:

Artigo $6^{\circ}-$ As escolas indígenas, respeitadas as normas específicas de funcionamento, desenvolverão suas atividades de acordo com o proposto no projeto pedagógico e regimento escolar, com as seguintes prerrogativas:

I - organização das atividades escolares, respeitando-se o fluxo das atividades econômicas, sociais, culturais e religiosas e

II - duração diversificada dos períodos escolares, ajustando-se às condições e especificidades próprias de cada etnia ou comunidade indígena.

Parágrafo único: A formulação do projeto pedagógico, próprio por escola ou por etnia, com anuência das Comissões Étnicas Regionais e do Conselho Geral do Núcleo de Educação Indígena, terá por base:

1. os referenciais curriculares indígenas;

2. as diretrizes curriculares nacionais referentes a cada etapa da educação básica;

3. os modos próprios de produção e transmissão de saberes de cada etnia;

4. as características próprias das escolas indígenas em respeito à especificidade étnico-cultural de cada etnia ou comunidade;

5. a realidade sociolinguística em cada situação;

6. a produção e a utilização de materiais didático-pedagógicos, que expressem metodologias que privilegiem processos específicos de aprendizagem, com conteúdos específicos do universo sociocultural de cada povo indígena;

7. a participação da respectiva comunidade ou etnia indígena.

Quanto à gestão da escola, a Resolução criou o cargo de vice-diretor, que se subordina à Diretoria de Ensino da região administrativa em que se encontra a aldeia. Este cargo, assim como a docência nas escolas, deve ser exercido por indígenas. A atribuição de aulas deverá respeitar as seguintes normas: na educação infantil e no ciclo I do ensino fundamental, a docência deverá ser exercida por portadores de diploma do Curso Especial de Formação em Serviço de Professor Indígena e, no ciclo II do ensino fundamental, assim como no ensino médio, o professor deve ser portador de diploma de licenciatura plena ou de Curso Especial de Formação em Serviço de Professor Indígena, em nível superior, desenvolvido pela Secretaria de Educação.

Em seu artigo $8^{\circ}$ está estabelecido que os espaços físicos das escolas deverão ser planejados, dimensionados e organizados de forma a atender às especificidades da proposta pedagógica da escola, aos recursos e materiais didáticos existentes, às necessidades dos educandos e às práticas sócio-culturais, econômicas e religiosas que caracterizam a etnia indígena atendida, ouvida a comunidade.

Se a legislação é clara a respeito das características e do funcionamento das escolas nas aldeias, indicando avanços consideráveis relativamente 
ao que existia antes dos anos 90, na prática nem tudo o que nela está contemplado é cumprido, como é possível constatar por meio de vários estudos sobre o tema (Grupioni, p. 2008; Lana, p. 2009; Mindlin, Muñoz, Azevedo, 2002; Lopes da Silva, p. 2000) e de observações e entrevistas realizadas por mim na aldeia Krucutu. É o que passo a abordar a seguir.

\section{A implementação da política de educação escolar indígena: questionamentos gerais presentes na literatura pertinente}

Considerando a literatura existente sobre a implementação das políticas voltadas para a educação escolar indígena, observa-se que as dificuldades apontadas resultam não apenas da não observância da legislação vigente por muitos governos estaduais e municipais, mas também pela dinâmica por ela assumida na implementação das políticas.

Primeiramente, como mostra Grupioni (2008), ao contrário do que preconizam as legislações internacional e nacional, não se criou no Brasil um sistema próprio para cuidar da educação indígena, e o que ocorreu foi sua inserção no sistema nacional de ensino. Neste sentido, embora se reconheça que a transferência de responsabilidades da Funai para o MEC tenha um lado positivo, na medida em que representou uma mudança na concepção de educação para os povos indígenas e excluiu a representação catequética do processo, implicou, como já referido, a estadualização das escolas e, em muitos casos, a sua municipalização, sem que fossem criados mecanismos que assegurassem o cumprimento dos novos princípios que se estabeleciam para a educação escolar indígena.

Em uma avaliação feita por Mindlin, Munõz e Azevedo (2002, p. 108-109), esta transferência de responsabilidades é "o ponto mais frágil" dessa política, pois "poucos Estados estão preparados para essas tarefas, menos ainda os municípios". Além disso, prosseguem os autores, "no plano regional e local, as pressões econômicas contrárias aos índios são grandes, influenciam governos e podem prejudicar a educação escolar indígena ligada à cidadania, à defesa de terras e dos direitos".

Grupioni (2008, p. 101) agrega um outro fator aos acima indicados referindo-se à subordinação das políticas de Estado aos processos eleitorais em que técnicos e especialistas nos órgãos responsáveis pela educação indígena são frequentemente substituídos por outros que desconhecem os programas, o andamento do processo e, em muitos casos, a problemática indígena.

Lopes da Silva (2002, p. 111), por sua vez, critica o excesso de normatizações que, ignorando os preceitos específicos garantidos pela legislação, impõem às escolas indígenas as mesmas regulamentações a que está submetida a administração da educação brasileira e, pior, segundo os mesmos princípios, desconsiderando os direitos indígenas.

Acerca dessa questão, há inúmeros exemplos tanto de desrespeito ao calendário indígena, no que se refere aos seus rituais, à sazonalidade do trabalho agrícola (onde este existe), quanto a aspectos específicos da 
cultura de cada povo e à forma considerada mais adequada para conduzir o processo pedagógico na escola (Grupioni, 2008; Lana, 2009).

Em sua dissertação de mestrado, Lana (2009) aborda, entre outras, as questões relativas ao desrespeito ao calendário escolar e as tentativas de estender para as escolas das aldeias as práticas avaliativas que compõem a gestão educacional no Brasil, mostrando-nos a sua inadequação para a realidade indígena através de depoimentos colhidos junto a professores e vice-diretores de escolas. Entre vários, cito o da vice-diretora da aldeia Krukutu, referindo-se primeiramente à imposição do calendário escolar e, em seguida, fazendo uma apreciação acerca da avaliação do Estado (Saresp):

[...] não podemos fazer do nosso modo [...] temos que seguir as regras dos órgãos oficiais de ensino, até mesmo o calendário escolar segue o mesmo das escolas não indígenas. Uma vez uma diretora de ensino disse que talvez pudéssemos trocar o período de férias de janeiro pelo mês de abril e, assim, cumprir com nossos rituais. Mas isto não foi possível, porque a Diretoria de Ensino não permitiu. Disseram que isto não existe. ( Lana, 2009, p. 126).

Também, certas festas indígenas que os professores querem promover com os alunos, considerando o caráter intercultural da educação diferenciada, quando têm duração de dois dias, por exemplo, devem ser realizadas em dois sábados sucessivos, para que se possa respeitar o domingo como dia de descanso do professor, contratado pelo Estado.

Com relação à aplicação das provas do Saresp nas escolas indígenas, diz a vice-diretora:

Se a prova que o governo aplica é para medir a qualidade do ensino nas escolas públicas, não entendo a necessidade desse tipo de avaliação em uma escola indígena, e, por outro, as crianças indígenas não estão preparadas para esse tipo de avaliação. Porque para os professores indígenas o currículo deve seguir o curso natural, quando os alunos avançam, avançamos juntos, não tem que enquadrar o ensino [...] o indígena não deve ser avaliado assim. Os brancos inventam uma sigla qualquer para medir o desenvolvimento escolar, pela qual se exige que os alunos tenham que alcançar isso ou aquilo. Mas, para nós, isso não importa. (Lana, 2009, p. 123).

Em uma visita realizada por mim à aldeia em maio de 2009, essa vice-diretora, referindo-se a outra modalidade de avaliação, isto é, aquela que é interna, elaborada e aplicada aos alunos pelo próprio professor, além de discordar de sua adequação, ressente-se da obrigatoriedade de que se reveste: "Temos que enviar as avaliações dos alunos a cada dois meses para a diretoria de ensino, mas nós não queremos dar notas aos alunos, isto não faz sentido para nós. Cada criança tem o seu tempo para aprender" (entrevista realizada em maio de 2009). Como se pode observar, não se trata apenas de uma crítica às modalidades de avaliação existentes hoje no sistema nacional de ensino, mas à própria lógica que orienta esta prática, fundada na homogeneização que se supõe existir na disposição das crianças para aprender. 
A formação de professores indígenas, por sua vez, enfrenta obstáculos difíceis de serem equacionados dentro da orientação geral que lhe tem sido imprimida pelas secretarias de Educação responsáveis por sua oferta. Primeiramente, diversos estudos e pesquisas mostram que há mais escolas do que professores, indicando um descompasso entre o número de professores indígenas formados nestes cursos e as necessidades das aldeias (Grupioni, 2008; Lana, 2009). Além disso, a forma como foi definida a educação escolar diferenciada pressupõe um perfil de professor que tenha domínio da língua portuguesa, de um dado repertório acerca dos conhecimentos ditos universais e, ao mesmo tempo, conhecimentos relativos à língua, cultura e história da etnia à qual pertence.

Com a reduzida carga didática prevista na maior parte dos cursos de formação oferecidos aos indígenas, isto se torna muito difícil, senão impossível. ${ }^{1}$ Por outro lado, o conhecimento indígena não está formalizado para que possa ser trabalhado como conhecimento escolar. Tampouco os professores em processo de formação são "especialistas" ou dominam completamente os conhecimentos de sua etnia, o que significa que eles têm que acessar junto aos mais velhos esses saberes, para poderem transmiti-los aos seus alunos e transpô-los para o registro escrito, tendo em vista a elaboração de material didático específico, tal como dispõe a legislação.

Este trabalho de pesquisa e sistematização implica, como diz Gallois (1996, p. 17) referindo-se ao esforço de jovens professores Wajãpi nesta direção, não somente a "compilação de saberes 'dos antigos', ou sua mera transcrição, mas envolve uma reflexão nova, atual, sobre eles, para que os Wajãpi possam equacionar o que eles chamam dos 'dois' caminhos (conhecimentos e práticas tradicionais, por um lado, e novos conhecimentos e práticas, por outro lado)".

Isto coloca em pauta o perfil desse professor que se pretende formar, acrescentando-lhe a capacidade de ser também um pesquisador e não mero transmissor do conhecimento acerca de sua etnia. Muitos cursos de formação não contemplam esta dimensão e tampouco têm profissionais versados sobre a questão indígena que lhes permita levar adiante tal empreendimento.

Com estas limitações, o uso de material didático específico a cada etnia fica comprometido, assim como o registro escrito de suas línguas, que depende de esforços empreendidos conjuntamente com linguistas preparados para lhes ajudar neste empreendimento.

Outro aspecto relativo à implementação dessa política e que se observa em muitos trabalhos sobre o tema é a ausência de um sistema de informações sobre o conjunto das escolas indígenas e o ensino nelas desenvolvido, como mostra Grupioni (2008), em detalhes: "O MEC segue ano a ano coletando informações sobre as escolas indígenas por meio do Censo Escolar, mas a maior parte destas informações não é sequer trabalhada, permanecendo inacessíveis no cadastro nacional das escolas do País." Da mesma forma, dados do Inep apresentam distorções, como as apontadas através de verificação realizada pela Comissão Geral de Educação Escolar
${ }^{1}$ Ver, a este respeito, Grupioni (2008), especialmente o capítulo IV. 
Indígena (CGEEI), em que foram incluídas como indígenas 82 escolas não indígenas, produzindo uma inflação de 37.000 alunos índios que estariam frequentando as escolas nas aldeias. O autor relata uma situação ocorrida em reunião com o secretário da Secad em 2007, onde professores indígenas e organizações não governamentais reivindicaram a realização de um novo censo escolar indígena como instrumento de avaliação e monitoramento da política de educação escolar indígena. O secretário teria então argumentado ser desnecessário, pois o Censo Escolar (nacional) fornecia de modo satisfatório as informações necessárias para subsidiar as ações de educação indígena (Grupioni, 2008, p. 106).

Estes são exemplos das dificuldades enfrentadas por aqueles empenhados em fazer cumprir a legislação existente. Penso, no entanto, que se esta situação evidencia as limitações do Estado e seus agentes em se relacionar com as comunidades indígenas, suas razões vão muito além das (in)disposições de grupos partidários, de grupos de interesses econômicos e mesmo de indivíduos que influenciam e/ou se ocupam da operacionalização das políticas voltadas para esses povos. Trata-se, antes, de problemas que emergem quando reivindicações da sociedade são assimiladas pelo Estado e transformadas em políticas públicas. Em texto já publicado (Bruno, 2009), onde discuto a relação entre poder político e sociedade, abordo as políticas sociais do Estado como expressão da face coercitiva do poder, em que as populações por elas focalizadas nunca constituem o sujeito das ações ou decisões que lhes atingem, mas objeto, ainda que essas políticas sejam respostas às suas lutas contra situações às quais se encontram submetidas e que julgam inaceitáveis.

No caso da educação escolar indígena, observa-se processo semelhante, em que os gestores das políticas julgam ser eles os agentes mais indicados para estabelecer prioridades e definir padrões de excelência relativos aos processos e resultados da educação indígena.

Como bem colocou o professor guarani Sérgio Lira, da Aldeia Uruity, situada no município de Miracatu:

O cumprimento das leis depende de muita gente, o que torna difícil sua execução. Em algumas ocasiões somos ouvidos, como determina a lei, o que não garante que as coisas sejam feitas como o acordado. Significa que quando somos chamados para dar nossa opinião, é claro que somos ouvidos, mas é somente uma formalidade, pois no final, os órgãos governamentais decidem e nós temos que obedecer, ou seja, nossa participação não muda nada (cf. Lana, 2009, p. 122).

Se estas situações se inscrevem no âmbito das relações entre Estado, secretarias, gestores do sistema educacional e grupos indígenas envolvidos diretamente com a questão da educação escolar indígena diferenciada, há outros aspectos que suscitam uma série de indagações.

O direito indígena à educação escolar diferenciada não foi uma reivindicação de todas as etnias e grupos indígenas existentes no País. No entanto, quando se transformou em política estatal, disseminou-se por diversas comunidades que não a reivindicavam, provocando resistências 
e desconfiança. Assim, o que se observa é que entre os próprios índios não há consenso acerca da importância da educação diferenciada, de como deve se organizar ou do lugar que deve assumir na formação das novas gerações. Esta situação se verifica tanto entre as diferentes etnias indígenas existentes no País quanto no interior de um mesmo grupo ou aldeia. Há inclusive aqueles que rejeitam a escola e cujos filhos não a frequentam.

\title{
Educação escolar diferenciada e as polêmicas que suscita no interior das aldeias
}

A educação diferenciada pressupõe o ensino bilíngue e o desenvolvimento de conteúdos que envolvem tanto o saber indígena e sua cultura quanto os conhecimentos ditos universais. Em torno dessas características estabelecidas na legislação desenvolve-se um debate no interior das aldeias, longe de ser resolvido. Enquanto muitos membros das comunidades indígenas defendem a escola nestes moldes outros a questionam, ambos com argumentos fortes.

Em sua defesa, apresento os argumentos de alguns professores guarani. Sérgio Lira, por exemplo, afirma:

\begin{abstract}
Na época que era estudante e era obrigado a frequentar uma escola não indígena, sofria muito. Os professores não sabiam como lidar com a gente, e nós não entendíamos as regras, o modo de ensino branco. [...]. Os outros alunos deixavam a gente de lado, nos xingavam, às vezes, até agrediam, porque achavam que éramos estranhos. Por isso, muitos de nós nunca consegui sequer concluir o ciclo básico do sistema de educação não indígena. Foram tempos muito difíceis (cf. Lana, 2009, p. 114).
\end{abstract}

Para este professor, contratado pelo Estado para lecionar a crianças de $1^{\mathrm{a}}$ a $4^{\mathrm{a}}$ série na aldeia onde mora, o fato de a escola estar localizada dentro da aldeia e ter professores indígenas facilita o aprendizado das crianças. Em outra situação (cf. Grupioni, 2008, p. 188) ele defendeu a inserção da língua e da cultura guarani na escola indígena, argumentando ser esta uma forma de se fortalecerem ante a cultura dos juruá (brancos), embora não deixe de ver as consequências que resultam da inserção da escola na aldeia, como procuro mostrar adiante.

Nas palavras da professora Poty Porã, da escola da aldeia Tekoá Ytu, situada no Jaraguá, a importância de se ensinar às crianças a cultura e a língua guarani na escola decorre do fato de ser esta uma maneira de reforçá-las e valorizá-las entre as novas gerações: "[...] a maioria dos professores, pelos menos aqueles com quem tenho contato, inclusive de outras aldeias, pensa como eu. A gente quer trabalhar a língua guarani, a gente quer trabalhar a matemática guarani, a gente quer trabalhar com as brincadeiras guarani, a gente quer reforçar a cultura."

Com relação à importância do ensino da língua guarani, diz esta professora: 
Eu acho que se a criança aprende a escrever primeiro em guarani, ela vai ter mais orgulho da língua, ela vai ter menos perigo de perder essa língua, porque a gente sabe que quando o pessoal é alfabetizado numa língua estrangeira, aquela língua estrangeira acaba se tornando mais importante do que a língua materna, já que é uma língua escrita. (cf. Testa, 2008, p. 303).

Neste depoimento há muitas questões articuladas, entre elas a importância conferida à palavra escrita. No momento, destaco apenas sua defesa da inserção da cultura e da língua guarani nos processos cotidianos de aprendizagem na escola, marcando o caráter diferenciado dessa educação, bilíngue e intercultural.

Esta valorização das atribuições da escola diferenciada, como já referido, enfrenta oposição de lideranças e pais de alunos, inclusive no interior de uma mesma comunidade, como mostram pesquisas já realizadas sobre esta questão (Paladino, 2001; Grupioni, 2008; Testa, 2008; Lana, 2009). Enquanto professores e algumas lideranças indígenas valorizam a escola como espaço permeado pela língua e pela cultura de suas comunidades, tendo em vista preservar e/ou recuperar aspectos que julgam já esquecidos ou perdidos pelas novas gerações, muitos pais discordam, vendo esta proposta não só desnecessária como inadequada.

Argumentam estes que o ensino do português e dos conhecimentos da sociedade envolvente, por serem muito importantes para que as novas gerações possam enfrentar em melhores condições os desafios que esta lhes impõe, deve ser o principal objetivo senão o único dessa educação. O conhecimento da língua portuguesa, assim como os conteúdos científicos produzidos pela sociedade ocidental, constitui um instrumento fundamental para a sobrevivência dos jovens numa sociedade tradicionalmente hostil aos povos indígenas. Assim, a escola não deveria ocupar o tempo das crianças e dos jovens com ensinamentos da própria cultura, tampouco de seu idioma. Argumentam que o modo de ser guarani, seus costumes, história e sabedoria são aprendidos na casa de reza, na comunidade, na família, nunca na escola, que identificam como coisa de branco, embora necessária no sentido acima apontado.

Testa (2008, p. 303) cita o relato da professora Poty Porã sobre uma reunião ocorrida na aldeia Tekoá Poran, onde estavam presentes algumas de suas lideranças, que afirmavam "que escola boa é escola igual [à dos] não indígenas, inclusive com professores não indígenas, pois esperavam que a escola fosse um espaço para aprender os conhecimentos não indígenas, e não para aprender a ser guarani".

Em meu entender, não se trata de secundarizar a importância da própria cultura e idioma, mas de afirmar um lugar específico para a escola na aldeia, questionando o seu caráter intercultural tal como definido nos termos da legislação. Minha hipótese acerca da defesa do caráter juruá dessa escola expressa um entendimento da função dessa instituição típica da sociedade ocidental, qual seja, conferir às novas gerações os instrumentos adequados para que possam enfrentar de forma menos dolorosa os desafios que a interação com a sociedade envolvente lhes impõe. Seria esta a sua função. 
A educação guarani, enquanto um processo muito mais vasto do que a escolarização, inclui outras formas de produção, aquisição e transmissão de conhecimento, o que faz com que seja um atributo da própria comunidade e da família e não deve ser delegada a uma instituição que não controlam e lhes é estranha.

Trata-se certamente de uma hipótese que, se não tenho condições de desenvolvê-la no momento, me permite colocar em suspenso certezas presentes no debate acerca da educação escolar indígena diferenciada e do papel que deve assumir a escola no interior das aldeias. Para tanto, penso ser importante trazer para o debate as concepções guarani de conhecimento e de processo de aprendizagem.

\section{Cultura, conhecimento e aprendizagem entre os guarani}

As sociedades indígenas no Brasil, em especial os guarani, mesmo depois de cinco séculos de convivência com a sociedade nacional, cujas estratégias de contato oscilaram entre o genocídio e a indiferença, passando pela violência simbólica de lhes negar estatuto de povos de cultura ou, ainda, pelas tentativas de cooptação de suas lideranças por agências estatais, não só continuam a existir como não se tornaram iguais a nossa. Esta situação, a meu ver, indica que não estamos diante de populações amorfas passíveis de serem moldadas por forças externas, mas que sua cultura é uma realidade dinâmica que se reinventa permanentemente, especialmente quando em contato com outras que lhes são não só estranhas como hostis. A cultura enquanto conceito expressa, como bem formula (Sahlins, 1997, p. 41), um fenômeno único que distingue os homens dos animais: "a organização da experiência e da ação humanas por meios simbólicos" - experiência e ação pautadas por regras, princípios e valores que, embora forjados na construção de estratégias históricas de sobrevivência de grupos e sociedades determinadas, estão inelutavelmente vinculados a processos mais amplos e universais. Isto significa considerarmos as diversas culturas produzidas na história humana como algo que, a despeito de suas diferenças, nos liga uns aos outros "numa unidade mais profunda e inalienável, qual seja, a nossa própria historialidade sapiental, uma velha senhora com idade presumível de 130 mil anos" (Assis Carvalho, 2003, p. 18).

Não se trata, portanto, de conceber as diferentes culturas como intocáveis e fechadas em si mesmas, o que, numa perspectiva relativista, as anularia mutuamente, tampouco de dissolvê-las numa suposta cultura universal, na realidade restrita à sociedade ocidental. Ao contrário, cabe considerar a capacidade que cada cultura apresenta de se apropriar de elementos de outras existentes com as quais se relaciona conferindo-lhe novos significados, adaptando-os aos seus próprios interesses e necessidades, revitalizando-se. Esta perspectiva não anula a possibilidade de se ver desaparecer sociedades ou comunidades inteiras com suas respectivas culturas, apenas sugere que, para que isso ocorra, é necessário destruir 
todas as condições em que surgiram e se desenvolveram suas práticas estruturantes. Estas se estabelecem tanto no âmbito da reprodução material de existência de uma dada sociedade quanto na esfera da política em que são definidas as regras através das quais se institui essa sociedade. Um guarani não deixa de sê-lo por usar roupas como as nossas, morar em casas de alvenaria ou freqüentar a escola, esta instituição tão central em nossa sociedade e que exatamente por isso carrega consigo a lógica social que lhe confere significado. Ao contrário, é possível pensar na capacidade dos guarani de apropriar-se dessa escola e fazê-la funcionar consoante seus propósitos e objetivos - esta possibilidade, no entanto, se existe não é dada, depende de muitos fatores e circunstâncias. Assim, penso ser a educação diferenciada indígena um campo fértil para pensarmos esta questão, e é nesta direção que caminham as reflexões que se seguem.

\section{A palavra como fundamento da humanidade guarani}

Pierre Clastres (1990), em seu livro A fala sagrada, analisa vários textos transcritos da cosmogênese guarani, entre eles um que considera fundamental para a compreensão do pensamento desse povo: trata-se do Ayvu rapyta, termo traduzido por Leon Cadogan (1959, apud Clastres, P., 1990) como fundamento da linguagem humana. Segundo P. Clastres (1990, p. 27), esse texto é central para os guarani, por ser, ao mesmo tempo, "o discurso de sua origem e a citação de seu destino". No primeiro verso, Ñamandu, pai dos primeiros deuses, pai dos últimos homens, desdobrando-se, produz o novo tempo, o calor vital, afastando o vento originário, gelado, sopro da morte. Este novo tempo se desdobra em duas imagens: a chama, como calor e luz, e a bruma, como signo da chama.

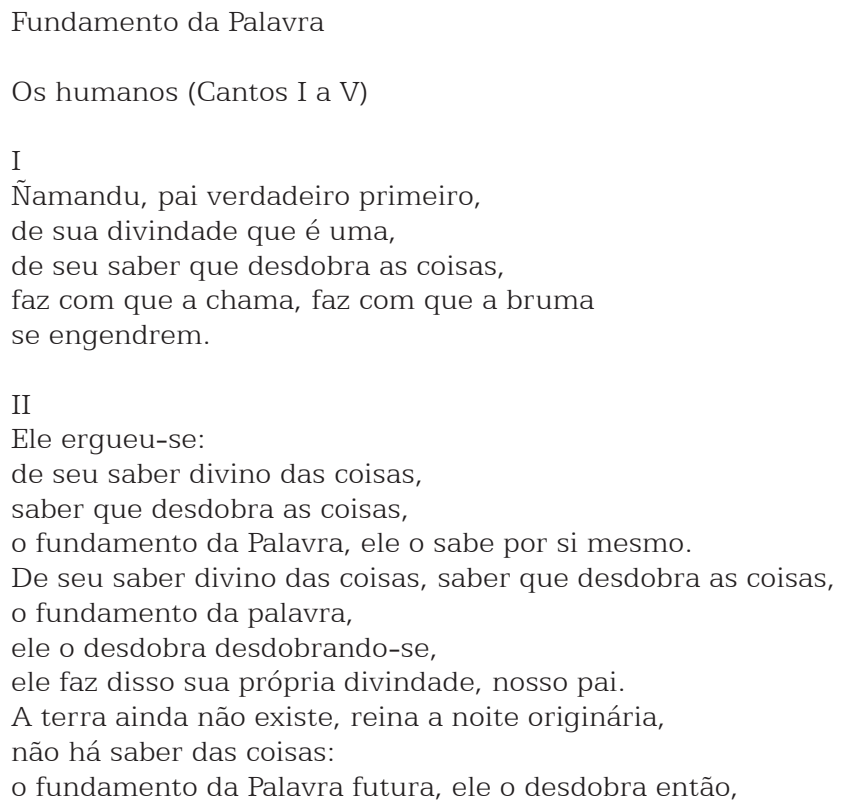


ele faz disso sua própria divindade, Namandu, pai verdadeiro primeiro.

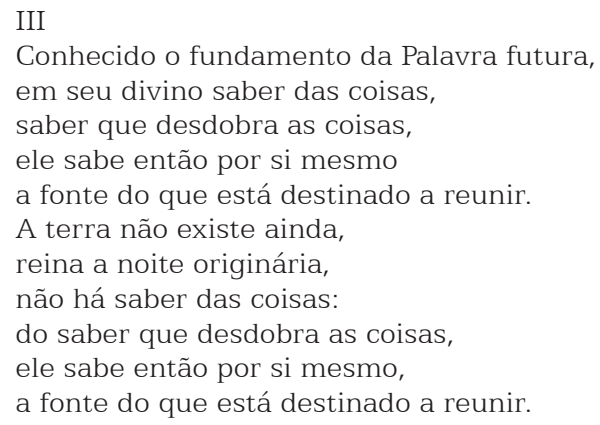

Segundo a interpretação de P. Clastres (1990, p. 27), neste mundo que está sendo criado observa-se "uma dupla cópia dessa bruma: de uma parte a neblina que os primeiros longos sóis fazem surgir acima das florestas no fim do inverno; de outra parte, a fumaça do tabaco que fumam em seus cachimbos os sacerdotes e os pensadores indígenas. A fumaça do tabaco repete a bruma original e traça, elevando-se do cachimbo, o caminho que conduz o espírito para a morada dos deuses".

No segundo verso, como mais um desdobramento do Deus Ñamandu, advém a Palavra, Ayvu, designando expressamente a linguagem humana. Como diz P. Clastres (1990, p. 27):

\begin{abstract}
Que a Palavra, como signo e substância do humano, seja de saída situada no coração da divindade do deus, determina por si mesma a natureza e a história do humano. Os homens definem-se como tais na relação que, através da mediação da Palavra, mantém com os deuses. Ayvu é a substância ao mesmo tempo do divino e do humano. Os homens só podem, por conseguinte, existir segundo sua própria substância conformando-se incessantemente à relação original que os liga aos deuses.
\end{abstract}

Se o lugar da Palavra é a humanidade dos homens, e aqui poderíamos entender esta humanidade como a consciência de que todos os humanos são portadores, isto os coloca em relação com a divindade o mais imediatamente possível. No entanto, a relação entre a humanidade dos homens e a divindade não recai sobre a relação de cada um com os deuses; antes, é "como ser coletivo que os homens - os índios guarani - afirmam e vivem a parte de divindade que contribui para constituí-los. Entre o Eu individual e o Eu dos deuses existe a tribo" (Clastres, P., 1990, p. 29). P. Clastres insiste neste aspecto dizendo ser a tribo não a adição dos indivíduos eleitos pelos deuses, mas o lugar da Palavra saída dos deuses, sendo na consciência dessa condição que reside o ser social dos guarani.

O autor relaciona essa consciência ao termo mborayu, que traduz como solidariedade tribal. Talvez se por tratar de um termo central na cosmologia guarani, diferentes significados lhe têm sido atribuídos por antropólogos e estudiosos desses povos. No primeiro dicionário guarani, até hoje considerado uma obra ímpar - Tesoro de la lengua guarani -, 
elaborado por Ruiz de Montoya, fundador das primeiras missões jesuíticas no Paraguai no século 17, o termo mborayu é traduzido como amor de Deus por suas criaturas, amor das criaturas por Deus (Clastres, P., 1990, p. 29). Leon de Cadogan (1959, apud Clastres, P., 1990), por sua vez, o traduz como amor ao próximo. No entanto, segundo P. Clastres (1990, p. 29), não é este "[...] o sentido que envolvia essa palavra para os guarani pagãos. Os missionários adotaram o termo mborayu para expressar a idéia cristã de amor, como adotaram o nome de Tupã, senhor da tempestade e do trovão, para dizer o nome de Deus". Hélène Clastres (1978, p. 116), em seu belo livro intitulado Terra sem mal, traduz mborayu por reciprocidade. Fausto (2005) o traduz por amor, explicando que este novo significado assumido pelo termo resulta do contato dos guarani com o cristianismo missionário e a experiência colonial que os levaram à crescente negação do canibalismo enquanto fundamento do poder xamânico e da reprodução social. Neste processo, substituíram-no pelo afeto, cujo nome é mborayu, traduzido por amor, onde ressonam as idéias originais de solidariedade e reciprocidade.

Na ausência de uma compreensão mais acurada desse termo entre os guarani contemporâneos, adoto aqui a tradução de P. Clastres, solidariedade tribal, embora a sugestão de H. Clastres, reciprocidade, pareça-me também adequada para compreender certas referências dos guarani ao processo de aprendizagem. Mais adiante vou retomar esta questão.

Por ora, é interessante notar que ayvu (palavra), como fundamento da humanidade dos homens, significa também linguagem e dizer, o que nos remete à noção de pessoa. Esta está centrada na idéia de alma, de espírito, que saído dos deuses vem habitar o corpo dos homens, sua moradia.

Em seu estudo sobre os guarani-mbya do litoral fluminense, Pissolato fala da existência de duas almas: ã e nhe'ë. A primeira está associada ao corpo, à sombra da pessoa, ao andar, ao estar em pé; a segunda, nhe'ë, muitas vezes também denominada ayvu (fala e/ou palavra), é central ao conhecimento, porque permite a comunicação não só com o divino, mas também entre os humanos. Nhe'ë constitui-se assim num princípio vital, sendo ao mesmo tempo condição de existência e princípio de divindade contido na humanidade mbya (Pissolato, 2007, p. 261).

Segundo a autora, esta concepção de alma é central às concepções acerca da produção, transmissão e aquisição de conhecimento, sendo ao mesmo tempo produto e condição de continuidade do fluxo de saberes e poderes enviados por Ñanderu a seus filhos e filhas mbya:

Produto, pois almas que tomam assento entre os vivos são potencialmente forças que vêm produzir alegria para os que as recebem; condição, porque é através de nhe'ë que seu portador adquire a capacidade de obter mais e mais entendimentos para fortalecer a própria existência - e possivelmente a de outros humanos. (Pissolato, 2007, p. 262).

Vejamos como esta concepção de alma se articula com a noção de conhecimento e de aprendizagem entre os guarani-mbya. 


\section{Conhecimento e aprendizagem}

Na perspectiva guarani, como se depreende do exposto acima, o conhecimento é uma exterioridade localizada nos deuses, cujas palavras fazem circular entre aqueles que deles se lembram e com eles se comunicam (Testa, 2008, p. 297). A terra dos homens, cheia de infelicidade e perigos, faz ser uma necessidade a permanente comunicação com os deuses, para deles receber forças, saberes existenciais e novas almas mbya, pois este mundo deixará de existir quando os deuses deixarem de enviá-las ou quando os homens não conseguirem mais ouvi-los e ser ouvidos por eles.

Assim, o conhecimento, cuja autoria é divina, possui uma dimensão infinita, e sua transmissão nunca se interrompe, de tal forma que o elemento enfatizado entre os guarani não é o acúmulo de saberes, mas a capacidade de acessá-los e fazê-los circular entre os parentes (Testa, 2008, p. 297). Neste sentido, é prestigiado aquele que demonstra tais capacidades mobilizando o saber: na cura, na liderança de um grupo ou no aconselhamento.

Tanto Pissolato (2007) como Testa (2008) propõem que se entenda a aquisição e a transmissão de conhecimento como atreladas à comunicação, que se desenvolve em dois eixos: um vertical, entre humanos e deuses, e outro horizontal, dos humanos entre si, salientando que parte importante do processo de conhecer se situa num universo de comunicação compartilhado. Em qualquer desses casos, o ponto central está nos caminhos de acesso ao conhecimento.

O eixo vertical da comunicação entre humanos e deuses pode ser estabelecido não só pelo xamã, mas por qualquer pessoa, posto que portadora do nhe'ë. Esta particularidade é importante para entendermos mais adiante um outro aspecto da pessoa, a sua autonomia não só como agente do aprender, mas também como sujeito portador de autonomia de julgamento.

Pissolato (2007, p. 317-318) relata uma conversa que teve com dois jovens irmãos guarani-mbya, na aldeia de Parati-Mirim, por ela pesquisada, um deles professor na escola da aldeia. Este jovem professor falava acerca das diferenças entre a escola dos brancos e a aprendizagem das crianças guarani-mbya. Nesta conversa ele afirma que, diferentemente do que ocorre em nossa sociedade, no meio guarani, não se aprende nos livros, se aprende na vida, colocando em destaque a dimensão da experiência individual desse aprendizado. Como diz a autora,

Por sua própria atividade subjetiva, cada Mbya adquire forças existenciais, o que parece ser afirmado numa frase que é consenso entre aqueles com quem vivi: cada um tem a sua sabedoria. Esta noção, ouvi-a em diferentes contextos, como na afirmação de Augustinho de que ele não poderia falar para seu filho o que efetivamente deveria fazer, já que este último é quem saberia do que lhe ocorre. (Pissolato, 2007, p. 317-318).

A sabedoria de cada um já está na criança, uma vez que ela é o corpo que abriga uma alma enviada por Nãnderu, mas, ao mesmo tempo, resulta 
da trajetória da pessoa no decorrer de sua vida. Esta sabedoria a entende Pissolato como sendo uma ciência da interpretação tanto da palavra divina quanto de acontecimentos vividos no cotidiano da pessoa.

Assim, não há um momento ou lugar específico para se comunicar com os deuses e, portanto, acessar o conhecimento, pois isto pode ocorrer na opy (casa de reza), rezando e fumando o petÿgua (cachimbo), durante um deslocamento territorial, em momentos em que se está caminhando pelas redondezas da aldeia, ou durante um sonho, quando se é surpreendido pelas palavras dos deuses. Assinala-se aqui a autonomia individual que marca esse processo, que resulta da disposição de estar atento às experiências vivenciadas.

A idéia de aprender na vida através de trajetórias prosseguidas no decorrer da vida está associada à idéia de mobilidade geográfica que tornou conhecidos os guarani, que, sempre em pé para falar com os deuses, circulam entre diferentes lugares e aldeias de parentes ou entre a aldeia e a cidade, mas associa-se também ao caminhar da alma, nhe'ë, entre os diferentes pontos de vista humanos e não humanos. Isto faz com que a aquisição do conhecimento seja sempre um processo relacional, um exercício permanente de almas e corpos em comunicação e deslocamento, onde se afirma a autonomia de cada um, conformando a pessoa na sua individualidade e fixando, ao mesmo tempo, seu pertencimento à comunidade dos que estão reunidos pela ayvu (Clastres, P., 1990, p. 31).

Se aprender na vida significa ser capaz de capturar através da concentração e do entendimento o que dizem as palavras divinas (eixo vertical), isto implica fazer circular esses saberes (eixo horizontal). Neste eixo de comunicação dos humanos entre si, afirma-se a dimensão social do processo de aprendizagem referido pelos jovens de que fala Pissolato, inscrita na afirmação se aprende ficando juntos. Estes dois eixos da comunicação permitem o entendimento (Pissolato, 2007, p. 318) que viabiliza o agir instruído. Neste sentido, não são apenas complementares, como diz Testa (2008), antes constituem dimensões indissociáveis de um mesmo processo: o ensino-aprendizagem.

Esta dimensão horizontal aparece nas conversas cotidianas entre pais e filhos, entre os mais velhos e os jovens, nas brincadeiras, nas sessões de aconselhamento acerca de sonhos e estados de espírito que os assaltam e no xamanismo. Não há um lugar específico para as sessões de aconselhamento; estas tanto podem ocorrer ao redor de uma pequena fogueira em frente à casa de uma família como nos encontros cotidianos entre parentes e na opy.

Um aspecto percebido por Pissolato (2007, p. 326) e que me parece importante destacar é que, "embora se possa diferenciar posições entre aquele que conta um sonho ou um acontecimento para ser instruído pelo xamã ou parente mais velho e aquele que aconselha, essas posições guardam sempre a possibilidade de alternância entre si", primeiramente porque, antes de interpretar e instruir, é preciso deslocar-se para o ponto de vista daquele que busca o aconselhamento. Assim, toda sessão dessa 
natureza inicia-se muitas vezes com uma conversa. A autora destaca que conhecimentos são sempre passíveis de se pôr à prova, e esta regra parece valer para toda e qualquer matéria da vida e graus de especialidade de saberes, inclusive para o xamã.

Assim, a boa conduta entre os humanos é aquela em que uns se aconselham com os outros. "Falar, contar, perguntar de modo brando é a maneira adequada de passar o próprio conhecimento e aprender com a sabedoria de outra pessoa" (Pissolato, 2007, p. 326). O reconhecimento de saberes, que envolvem também o benzer e a indicação de algum remédio que se dá a outra pessoa, ocorre na ação simultânea daquele que os detém e da pessoa que os solicita, de tal forma que a disposição para ajudar e o reconhecimento dessa capacidade do outro se constroem mutuamente (p. 329).

O tom dessas conversas e falas, nos diz a autora, é sempre suave e contínuo, e eu própria tive a oportunidade de assistir uma sessão de cura e, em seguida, de aconselhamento na opy da aldeia Tekoá Porã, no Jaraguá, em que não só o xamã mais velho mas outros mais jovens tomaram a palavra para sessões de aconselhamento, e o tom geral de todas as falas que presenciei era suave e calmo. Talvez esta forma suave e calma que caracteriza o aconselhamento se deva ao fato de a busca do conhecimento e a sua socialização entre os guarani, em qualquer domínio (o saber plantar, o saber curar, o saber brincar, o saber interpretar as palavras divinas), ter como objetivo fundamental produzir bem-estar, deixar as pessoas felizes e saudáveis, estados de espírito que constituem condições para que se queira permanecer na terra, entre os homens. Como se diz entre os guarani, "se a alma não se alegra ela morre e abandona este mundo" - e é preciso que as almas queiram aqui permanecer, para que a Terra continue a existir.

A sua conduta parece fundar-se numa solidariedade que se afirma em diferentes situações e dimensões da vida social e na reciprocidade de afetos e saberes. Segundo Pissolato (2007, p. 334), "o que os mbya fazem nessas sessões de falas é o que literalmente chamam de aconselharem-se (nhemongeta)", reafirmando o que disse o jovem professor da aldeia de Parati-Mirim: se aprende ficando junto.

No que se refere ao xamã, se ele é aquele capaz de acessar um saber especializado através das Belas Palavras com as quais se comunica com os deuses, nem assim ele deixa de ser contestado ou mesmo ignorado em determinadas situações.

Pissolato chama a atenção para o fato de a literatura existente sobre os guarani centralizar na figura do xamã o especialista na cura, dirigente da reza e orientador de um grupo de parentes em seus deslocamentos territoriais, a constituição e reprodução da organização social desse povo, em razão da sua relação com os deuses e do fluxo de capacidades e existências que dela se origina. A autora contesta esta centralidade a ele atribuída, e eu concordo com a sua ponderação baseada em dois argumentos fortes: primeiramente, diz a autora, "o conhecimento xamânico é algo percebido pelos guarani-mbya numa abrangência muito maior que a da atuação 
${ }^{2}$ Ver, sobre as transformações ocorridas no "modo de ser guarani", o artigo de Carlos Fausto (2005). propriamente dita da figura do xamã, que pode mesmo não existir em determinados contextos locais"; em seguida, propõe que o discurso que afirma o xamã como guardião da forma tradicional de viver, identificada com a vida dos "antigos", "só se constrói como uma perspectiva que estaria sempre em negociação com a realidade mais abrangente capaz de originar muitos pontos de vista que não aquele do xamã que encabeça um grupo em dado momento" (Pissolato, 2007, p. 338).

Se cada pessoa, como já referido acima, obtém conhecimento pela atividade de sua própria nhe'ë na relação estabelecida com os deuses e da qual advém a sua consciência, elemento mais fundamental de sua humanidade, o saber do xamã não é a única fonte à qual se pode recorrer, podendo até ser contestado em muitas situações. O entendimento acerca das questões existenciais, da cura de doenças e de processos que afligem as pessoas se faz a partir de diferentes pontos de vista, tanto na vertente vertical da comunicação quanto na horizontal, e isto impede que se estabeleça um padrão único de verdade, que, como sabemos, é a porta de entrada para todos os autoritarismos.

A autonomia individual, enfatizada na expressão "cada um tem a sua sabedoria", relativiza a centralidade do xamã e põe por terra a ideia, muito difundida entre nós, da submissão do indivíduo a um coletivo sufocante que caracterizaria as sociedades indígenas; da mesma forma, desmonta certas análises sociológicas que, como disse Lévi-Strauss (1996, p. 299), pintaram as sociedades primitivas "como esmagadas por uma tradição todo poderosa". Eu diria que esta tradição tão referida quando se fala das sociedades indígenas é muito mais expressão de nosso desconhecimento acerca da história, da dinâmica interna e dos processos de mudança que vivenciam essas sociedades do que uma realidade empiricamente dada. ${ }^{2} \mathrm{O}$ que quero destacar aqui é a sábia combinação que os guarani desenvolveram entre autonomia individual e reprodução da vida social consoante regras compartilhadas coletivamente. Esta sabedoria talvez a encontremos na concepção de pessoa portadora do nhe'ë (alma), princípio da individuação e da consciência de sua humanidade, que fixa ao mesmo tempo o pertencimento da pessoa à comunidade dos que são reunidos pela Ayvu (a palavra dos deuses), comunidade tecida tanto pela solidariedade quanto pela reciprocidade que ecoam no termo mborayu, afeto que os liga uns aos outros.

Assim, se podemos entender o significado atribuído pelos guarani ao termo "conhecimento" como uma ciência da interpretação, tal como propõe Pissolato, e, ao mesmo tempo, como relação, conforme sugere Testa (2008), sendo a aprendizagem decorrente de um processo de comunicação e deslocamento entre espaços e interlocutores humanos e não-humanos, qual o lugar da escola e da palavra escrita entre os guarani nossos contemporâneos? Penso não ser possível uma resposta única e tampouco encontrá-la através da reflexão teórica; antes, temos que observar e buscar na própria prática das comunidades indígenas as formas pelas quais elas vêm equacionando esta questão e quais serão os seus desdobramentos. 


\section{Algumas palavras finais}

Povo de vários deuses, livre da noção cristã de pecado, apesar de todo o esforço empreendido pelos jesuítas para nele incuti-la, o povo guarani, na sua relação com o divino, em nada se assemelha aos povos de religião monoteísta, marcados pelas atitudes de subserviência diante do divino. Como sugere P. Clastres (1990, p. 31), o canto sagrado que os guarani fazem subir até os deuses "não é um ato de fé, nem o suspiro angustiado da comunidade de crentes. Nele os homens antes afirmam o saber intransigente de sua própria divindade".

Sugiro que desta forma de pensar sua relação com os deuses decorra a concepção guarani de conhecimento, por sua vez vinculado à idéia de pessoa portadora de nhe'ë, alma recebida dos deuses e portadora da possibilidade imediata de comunicação com o saber divino, saber infinito que deve ser permanentemente acessado e distribuído/socializado, fazendo do conhecimento, antes de tudo, interpretação e relação, não expressão de uma verdade canônica. O objetivo: o viver bem, alcançar a felicidade de si e dos parentes, para que se queira permanecer vivo nesta Terra cheia de perigos e ameaças.

Meliá (1998) chama a atenção para as diferenças existentes entre a ação pedagógica para a alteridade tal como é concebida nas sociedades indígenas e nas chamadas sociedades modernas ocidentais. Nestas, a educação está marcada pela capacitação individual tendo em vista a competição no mercado de trabalho, com o objetivo de produzir e possuir bens, embora, como sabemos, nem sempre com o sucesso esperado.

A acumulação de conhecimentos e habilidades é o principal objetivo, ao mesmo tempo em que o saber não deve ser distribuído em condições de igualdade, posto que saber configura poder nas sociedades desiguais. Os métodos de ensino consagrados, o quadro disciplinar em que se organiza a escola, assim como as práticas avaliativas, reforçam e sustentam esta concepção de educação e a sua instrumentalização pelos centros de poder constituídos. O saber serve para conformar a natureza aos ditames de um sistema econômico que se estrutura e se desenvolve na desigualdade social e, ao mesmo tempo, para viabilizar o exercício da dominação de uns poucos sobre muitos.

Os antigos internatos onde muitos índios estudaram os preparavam dentro desta concepção, e, nesta medida, acabaram por determinar a saída de muitos deles para fora das suas comunidades; ao mesmo tempo, exatamente por terem passado por esta experiência, muitos professores lutam por uma outra educação e, hoje, são bastante ativos na defesa da escola indígena na aldeia em outros moldes.

Nas sociedades indígenas brasileiras e, no caso que aqui abordo, entre os guarani, a ação pedagógica integra várias dimensões da realidade social: a simbólica (a língua), a economia, o parentesco e a política. Nesta última dimensão, cabe salientar que se trata de uma dada forma de organização do poder que se manifesta sobretudo na sua face acolhedora e benevolente, permanecendo o poder político como um atributo 
exclusivo da sociedade sem que nenhuma instituição ou grupo social o monopolize (Bruno, 2009).

O modo como se vive esta organização social conforma uma pedagogia que busca desenvolver e manter as alteridades, o que talvez nos explique a razão pela qual puderam os guarani superar a prova do período colonial e os embates da assimilação e da integração de tempos mais recentes. A alteridade que cada povo indígena projeta e deseja para si confunde-se com a constituição da própria pessoa e reafirma o seu pertencimento ao grupo. Neste sentido, tem-se aí uma pedagogia em que a participação da comunidade no processo de ensino-aprendizagem é seu traço característico, e é esta participação que assegura uma alteridade a serviço da comunidade (Meliá, 1998, p. 6). Isto não implica a dissolução das subjetividades num coletivo homogeneizante, ao contrário, o que mais prezam esses povos é autonomia de cada pessoa e, fundamentalmente, a autonomia de julgamento.

Como mostra Pissolato, esta autonomia se observa no cotidiano das aldeias e para além de tudo o que já foi aqui referido; neste sentido, há um outro aspecto importante que diz respeito à atitude do xamã e dos mais velhos quanto às práticas de aconselhamento - estas só ocorrem quando solicitadas e, mesmo nestas situações, é preciso antes de tudo adentrar no ponto de vista do outro (o que o solicita) para poder compreender do que se fala. É o inverso da atitude invasiva que caracteriza os processos de ensino na escola ocidental, em que o professor ou o próprio Estado determina o momento, o conteúdo e a forma de transmitir conhecimento ao aluno, independentemente de qualquer ponto de vista que não o seu próprio ou daquele que lhe foi também imposto durante seu próprio processo formativo.

Nesta perspectiva, penso ter sido um equívoco (para dizer o mínimo) inserir a educação indígena no sistema nacional de educação, subordinado-a a normas e procedimentos que só têm sentido em nossa sociedade, sem esquecermos que mesmo este suposto sentido tem sido exaustivamente criticado desde o século 19, quando surgiram nas sociedades ocidentais os primeiros sistemas nacionais de educação - é oportuno lembrar aqui as obras de Paul Robin, Francisco Ferrer, Freinet, além de Ivan Illich e Paulo Freire, e das críticas de Bourdieu e Passeron.

Assim, não creio que tenhamos um modelo de escola para oferecer aos povos indígenas, tampouco estou certa de que podemos encontrar em suas sociedades respostas acabadas e modelos a serem transpostos para a nossa sociedade. No entanto, há um aspecto da educação guarani que gostaria de ressaltar e sugerir que nos debrucemos sobre ele: a rara sabedoria desses povos em combinar autonomia de julgamento e sentimento de solidariedade.

A ação pedagógica para a alteridade, tão repisada hoje pelos organismos internacionais que se ocupam da educação, não é uma descoberta feita pela sociedade ocidental e nacional para oferecer aos povos indígenas. Como escreveu Meliá (2008, p. 6), ao contrário: "é o que os povos indígenas podem ainda oferecer à sociedade nacional". 


\section{Referencias bibliográficas}

ASSIS CARVALHO, E. Enigmas da cultura. São Paulo: Cortez, 2003.

BRASIL. Constituição Federal. 1988.

. Decreto $n^{\circ} 23$, de 4 de fevereiro de 1991. Dispõe sobre as condições para a prestação de assistência à saúde das populações indígenas. Disponível em: < http://www.planalto.gov.br/ccivil_03/ decreto/1990-1994/D0023.htm>.

. Decreto $n^{\circ} 24$, de 4 de fevereiro de 1991. Dispõe sobre as ações visando a proteção do meio ambiente em terras indígenas. Disponível em: < http://www.planalto.gov.br/ccivil_03/ decreto/1990-1994/D0024.htm> .

. Decreto $n^{\circ} 25$, de 4 de fevereiro de 1991. Dispõe sobre programas e projetos para assegurar a autossustentação dos povos indígenas. Disponível em: < http://www.planalto.gov.br/ccivil_03/ decreto/1990-1994/D0025.htm>.

. Decreto $n^{\circ} 26$, de 4 de fevereiro de 1991. Dispõe sobre a educação indígena. Disponível em: <http://www.planalto.gov.br/ ccivil_03/decreto/1990-1994/D0026.htm>.

BRASIL. Ministério da Educação (MEC). Referencial Curricular Nacional para as Escolas Indígenas. Brasília, 1998.

BRASIL. Ministério da Educação (MEC). Secretaria de Educação Fundamental (SEF). Coordenação Geral de Apoio às Escolas Indígenas. Referenciais para a formação de professores indígenas. Brasília, 2002. Disponível em: <http://portal.mec.gov.br/seb/arquivos/pdf/ Livro.pdf $>$.

. Portaria Interministerial no 559, de 16 de março de 1991.

Cria a Coordenação Nacional de Educação Indígena e dá providências correlatas. Disponível em: <http://siau.edunet.sp.gov.br/ItemLise/ arquivos/notas/portInter559_91.htm?Time=11/3/2011\%20 10:30:36\%20PM> .

BRUNO, L. Poder político e sociedade: qual sujeito, qual objeto? In: BARTOLOZZI, E.; ANDRADE OLIVEIRA, D. (Orgs.). Crise da escola e políticas educativas. Belo Horizonte: Autêntica, 2009. 
CLASTRES, Pierre. A fala sagrada. Campinas: Papirus, 1990.

CLASTRES, Hélène. Terra sem mal: o profetismo tupi-guarani. São Paulo: Brasiliense, 1978.

FAUSTO, Carlos. Se Deus fosse jaguar: canibalismo e cristianismo entre os guarani (séculos XVI-XX). Mana: Revista de Antropologia Social, Rio de Janeiro, v. 11, n. 2, p. 385-418, out. 2005.

GALLOIS, D. T. Xamanismo waiãpi: nos caminhos invisíveis - a relação i-paie. In: LANGDON, E. J. M. (Org.). Xamanismo no Brasil: novas perspectivas. Florianópolis: Ed. UFSC, 1996. p. 39-74.

GRUPIONI, L. D. Benzi. Olhar longe, porque o futuro é longe: cultura, escola e professores indígenas no Brasil. 2008. Tese (Doutorado) Universidade de São Paulo (USP), 2008.

LANA, Eliana. Políticas públicas para a educação escolar indígena na América Latina: legislações de Brasil e Bolívia. 2009. Dissertação (Mestrado) - Universidade de São Paulo (USP), 2009.

LÉVI-STRAUSS, C. Tristes trópicos. São Paulo: Companhia das Letras, 1996.

MELIÁ, B. Educação indígena na escola. Conferência ministrada no I Congresso Internacional de Educação Indígena, Dourados (MT), 1998. Disponível em: <http://www.scielo.br/pdf/ccedes/v19n49/ a02v1949.pdf $>$

MiNDlin, B.; MUÑOZ, H.; AZEVEDO, M. M. (Orgs.). Apreciação das políticas públicas em educação indígena no período 1995-2002. Brasília: MEX/SEF, 2002. [Não publicado].

PISSOLATO, Elisabeth. A duração da pessoa: mobilidade, parentesco e xamanismo mbya (guarani). São Paulo: Unesp, 2007.

SAHLINS, M. O "pessimismo sentimental" e a experiência etnográfica: porque a cultura não é um "objeto" em via de extinção - Parte I. Mana: Estudos de Antropologia Social, Rio de Janeiro, v. 3, n. 1, p. 41-73, out. 1997.

TESTA, A. Q. Entre o canto e a caneta: oralidade, escrita e conhecimento entre os guarani-mbya. Educação e Pesquisa, São Paulo, v. 34, n. 2, p. 291-307, 2008. Disponível em: < http://www.scielo.br/ pdf/ep/v34n2/06.pdf>. 
Lúcia Bruno, doutora em Sociologia pela Universidade de São Paulo (USP), é professora livre-docente da Faculdade de Educação da USP e do Programa de Pós-Graduação em Integração da América Latina (Prolam/USP). lenuevo@usp.br

Recebido em 14 de setembro de 2011.

Aprovado em 19 de outubro de 2011. 